\title{
Keratolytic winter erythema
}

INSERM

\section{Source}

INSERM. (1999). Orphanet: an online rare disease and orphan drug data base. Keratolytic winter erythema. ORPHA:50943

Keratolytic winter erythema is a rare epidermal disease, characterized by recurrent centrifugal palmoplantar peeling and erythema presenting seasonal variation (cold weather). Skin lesions may spread to the dorsum of hands and feet and to the interdigital spaces. Lower legs, knees and thighs may also be involved. Episodes may be preceded by itch and hyperhidrosis. Skin biopsy reveals an epidermal spongiosis with clefting in the stratum corneum, followed by regrowth. Keratolytic winter erythema follows an autosomal dominant mode of transmission. 